\title{
Tropospheric carbon monoxide variability from AIRS under clear and cloudy conditions
}

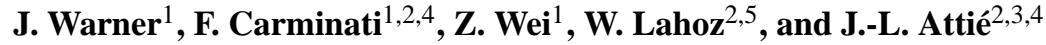 \\ ${ }^{1}$ Department of Atmospheric \& Oceanic Science, University of Maryland, 3433 Computer \& Space Sciences Bldg, \\ College Park, MD 20742, USA \\ ${ }^{2}$ CNRM-GAME, Météo-France and CNRS, UMR3589, Toulouse, France \\ ${ }^{3}$ Laboratoire d'Aérologie, CNRS, UMR5560, Toulouse, France \\ ${ }^{4}$ Laboratoire d'Aérologie, Université de Toulouse, CNRS, UMR5560, Toulouse, France \\ ${ }^{5}$ NILU, Norwegian Institute of Air Research, Instituttveien 18, Kjeller 2027, Norway
}

Correspondence to: J. Warner (juying@atmos.umd.edu)

Received: 6 May 2013 - Published in Atmos. Chem. Phys. Discuss.: 18 June 2013

Revised: 3 November 2013 - Accepted: 8 November 2013 - Published: 20 December 2013

\begin{abstract}
We study the carbon monoxide $(\mathrm{CO})$ variability in the last decade measured by NASA's Atmospheric InfraRed Sounder (AIRS) on the Earth Observing System (EOS)/Aqua satellite. The focus of this study is to analyze $\mathrm{CO}$ variability and short-term trends separately for background $\mathrm{CO}$ and fresh $\mathrm{CO}$ emissions based on a new statistical approach. The AIRS Level 2 (L2) retrieval algorithm utilizes cloud clearing to treat cloud contaminations in the signals, and this increases the data coverage significantly to a yield of more than $50 \%$ of the total measurements. We first study if the cloud clearing affects $\mathrm{CO}$ retrievals and the subsequent trend studies by using the collocated Moderate Resolution Imaging Spectroradiometer (MODIS) cloud mask to identify AIRS clear sky scenes. We then carry out a science analysis using AIRS CO data individually for the clear and cloud-cleared scenes to identify any potential effects due to cloud clearing. We also introduce a new technique to separate background and recently emitted $\mathrm{CO}$ observations, which aims to constrain emissions using only satellite $\mathrm{CO}$ data. We validate the $\mathrm{CO}$ variability of the recent emissions estimated from AIRS against other emission inventory databases (i.e., Global Fire Emissions Database - GFED3 and the MACC/CityZEN UE - MACCity) and calculate that the correlation coefficients between the AIRS CO recently emitted and the emission inventory databases are 0.726 for the Northern Hemisphere (NH) and 0.915 for the Southern Hemisphere (SH). The high degree of agreement between emissions identified using only AIRS CO and independent inventory sources demonstrates
\end{abstract}

the validity of this approach to separate recent emissions from the background $\mathrm{CO}$ using one satellite data set.

\section{Introduction}

Global long-term measurements of tropospheric carbon monoxide (CO) from space-borne instruments have been possible since year 2000 with the launch of the Measurement Of Pollution In The Troposphere (MOPITT) (Drummond, 1989) on the Earth Observing System (EOS) Terra satellite, followed by the Atmospheric InfraRed Sounder (AIRS) on Aqua (Aumman et al., 2003), the Tropospheric Emission Spectrometer (TES) on Aura (Beer, 2006), the Infrared Atmospheric Sounder Interferometer (IASI) on the European MetOp platform (Clerbaux et al., 2010), and future CO products from the Cross-track Infrared Sensor (CrIS) on SuomiNPP satellite. These measurements have advanced our understanding in many areas of science such as air quality and transport studies (Heald et al., 2003; Lin et al., 2012); field campaign support and validation (Fisher et al., 2010; Warner et al., 2007; Emmons et al., 2004, 2007); and model chemistry, transport, and data assimilation studies (Kim et al., 2013; Arellano et al., 2007; Pradier et al., 2006; Lamarque et al., 2004) that aim to improve the capability of air quality forecasts. 
There has been attention recently on the $\mathrm{CO}$ trend using satellite measurements, especially considering that the lifetime of MOPITT and AIRS has exceeded $10 \mathrm{yr}$ (Worden et al., 2013; He et al., 2013). These studies have found a decreasing trend in a number of regions that is possibly due to increased air quality standards and the recent economic slowdown. This study re-examines the short-term $\mathrm{CO}$ trends from AIRS with a focus on the discussion of the background $\mathrm{CO}$ and $\mathrm{CO}$ recent emissions. Separating $\mathrm{CO}$ recent emissions from the background is of interest in that the background $\mathrm{CO}$ variability can be used to validate modeled $\mathrm{CO}$ climatology, which helps to improve air quality models and eventually benefit air quality forecasts. Inventory studies based on $\mathrm{CO}$ measurements largely rely on the use of inverse modeling and top-down estimates (Pfister et al., 2005; Arellano et al., 2006; Kopacz et al., 2010). The capability to separate the recent emissions from the background $\mathrm{CO}$ may also lead to an automated real-time detection system for fire emissions. Although near-real-time fire detection from the Moderate Resolution Imaging Spectroradiometer (MODIS) products based on the surface biomass and temperature properties is available (Justice et al., 2002), the CO-based fire detection has not been used hitherto.

AIRS is a grating instrument on board EOS/Aqua satellite, launched on 4 May 2002 by NASA. As a thermal hyperspectral sensor, AIRS has more than 2000 channels available for applications including weather, climate, and air quality studies. AIRS provides twice daily and near-global coverage of tropospheric CO for the period since 2002, and the CO climate record will continue with IASI instruments with current and planned missions started in late 2006 and planned to last $15 \mathrm{yr}$, and possibly CrIS. This study uses the operational AIRS version 5 (V5) CO products that are based on AIRS science team physical algorithms and distributed by the NASA GSFC's Earth Sciences (GES) Distributed Active Archive Center (DAAC).

Satellite measurements using the thermal spectral regions are affected by the presence of clouds, and, therefore, it is necessary to remove the effects of clouds before retrieving many geophysical properties. Techniques to remove cloud contamination include the identification and removal of the entire pixel that contains clouds, referred to as cloud detection. Another approach is to reconstruct clear column radiances that would have been there if there were no clouds, referred to as cloud clearing. Many earlier studies (Smith, 1968; Chahine, 1974, 1977; McMillin et al., 1982; Susskind et al., 1998) built the foundation for the cloud clearing technique that was later adapted by the AIRS team.

The AIRS L2 retrieval algorithm utilizes cloud clearing to remove cloud contamination in the radiances, and this helps to increase the L2 data coverage significantly to a yield of $50-70 \%$ of the total measurements. AIRS's cloud clearing uses nine neighboring pixels with different cloud fractions, as well as the microwave sounder Advanced Microwave Sounding Unit (AMSU) data, to solve for AIRS clear radiances
(Susskind et al., 2003). Cloud clearing utilizes the contrast in the cloud fraction between neighboring pixels and can recover non-uniform cloudy pixels with up to $80 \%$ of cloud cover. Sounding is performed on a $45 \mathrm{~km}$ field of regard (FOR), which is defined by the size of the AMSU footprints. For quality assurance purposes, it is important to understand the effects of the cloud clearing on the overall quality of the retrievals. To select AIRS clear pixels, we use the collocated MODIS cloud mask, which applies a number of thresholds from 14 different spectral channels in both visible and thermal regions to identify clouds in a $1 \times 1 \mathrm{~km}^{2}$ field of view (FOV; Ackerman et al., 1998).

We first describe, in Sect. 2, the method to collocate AIRS single-view pixels with the Aqua MODIS cloud mask to identify AIRS clear pixels. We then analyze AIRS CO variability using clear sky pixels identified in the previous section and the cloud-cleared pixels from the L2 products in Sect. 3. In Sect. 4, we introduce a new statistical method to separate $\mathrm{CO}$ recent emissions from the background concentrations in AIRS data and compare the results with known CO emission inventories, before summarizing this study in Sect. 5 .

\section{Identifying AIRS clear-sky coverage}

To select AIRS clear sky pixels, we use the MODIS cloud mask (MYD35_L2) (ftp://ladsftp.nascom.nasa.gov/allData/ 5/MYD35_L2/) taking advantage of the fact that MODIS is on the same Aqua satellite platform as AIRS. An example in Fig. 1 illustrates the method we used to collocate the AIRS and MODIS pixels. We first select granules (units of data stored as files for satellite data) that coincide in time from the two data sets, and then match one center pixel of a granule from each sensor using geo-location information. There are a total of 240 granules a day for AIRS and 288 granules a day for MODIS. A predetermined index system, marked as colored boxes in Fig. 1, is then used to include a certain number of the surrounding MODIS pixels for each AIRS pixel. Figure 1 illustrates the method of the AIRS vs. MODIS collocation where the small solid dots (black or colored inside the boxes) are the center locations of MODIS pixels, the blue circles the center locations of AIRS pixels, the green squares the collocated nearest MODIS pixels, and the triangles the center locations of the boxes used for all the MODIS pixels in each AIRS pixel. This index system was developed based on a fixed relationship between the AIRS and MODIS instrument viewing angles, which will not change during the lifetime of the sensors. Note that some MODIS pixels are not included between the rectangular boxes to account for the gaps between AIRS scan lines (see Aumann et al., 2003, on AIRS instrument design).

AIRS single FOVs of $\sim 13.5 \mathrm{~km}$ at nadir are used to collocate with MODIS $1 \mathrm{~km}^{2} \times 1 \mathrm{~km}^{2}$ pixels. We define an AIRS clear pixel when more than $99 \%$ of MODIS pixels inside the AIRS FOVs are flagged to be clear. AIRS clear coverage 


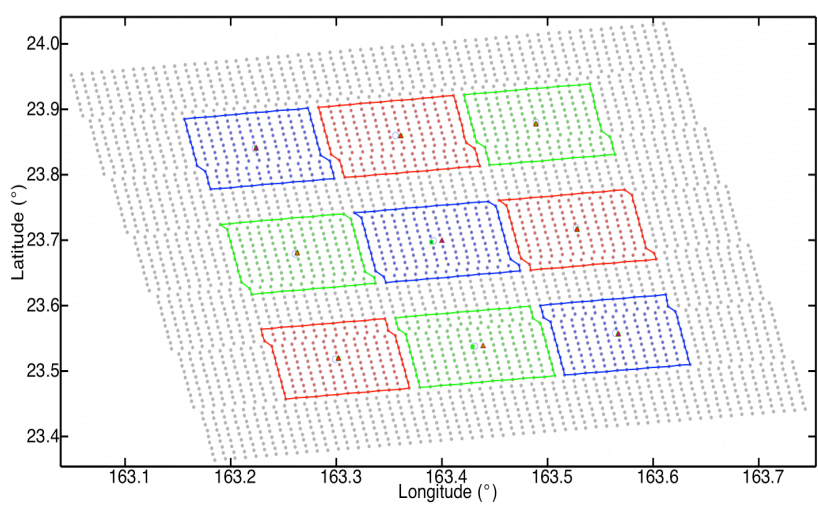

Fig. 1. The method of the AIRS vs. MODIS collocation where the small solid dots (black or colored inside the boxes) are the center locations of MODIS pixels, the blue circles the center locations of AIRS pixels, the green squares the collocated nearest MODIS pixels, and the triangles the center locations of the boxes used for all the MODIS pixels in each AIRS pixel.

defined by the MODIS cloud mask for 4 March 2006 is shown in blue in Fig. 2 top panel, and the total clear sky pixel ratio is approximately $14.9 \%$. If we choose to define a clear AIRS pixel when all MODIS pixels are flagged clear, there would be only $13.3 \%$ clear AIRS pixels per day. AIRS clear coverage is also defined by AIRS-measured radiances, instead of by the MODIS cloud mask, as part of the L2 products. The blue pixels in Fig. 2 middle panel show AIRS L2 clear sky cases (when CloudFraction $=0$ in the L2 product), and the total clear sky pixel ratio is $\sim 24.3 \%$, which tends to overestimate the amount of clear coverage compared to using the MODIS cloud mask as in Fig. 2 top panel. AIRS L2 cloud ratio products can be compared to those defined by the MODIS cloud mask only under clear sky conditions because the MODIS sub-pixel $\left(1 \times 1 \mathrm{~km}^{2}\right)$ cloudiness is unknown. The clear sky coverage differences between MODIS and AIRS L2 are shown in Fig. 2 bottom panel, where the blue pixels represent the cases when both MODIS and AIRS L2 detect clear sky ( $\sim 9.5 \%$ of AIRS total daily pixels). The green pixels are when MODIS detects clear sky, but AIRS L2 failed to identify clear sky cases $(\sim 5.4 \%)$, whereas the magenta pixels are clear sky detected by AIRS L2, but not verified by MODIS $(\sim 14.8 \%)$.

The low clear sky coverage shown as blue pixels in the Fig. 2 top panel confirms the need for cloud clearing in the case of AIRS. This is not only because the clear sky coverage is otherwise only approximately less than $13 \%$ (in the case of $100 \%$ MODIS pixels being clear in each AIRS pixel), but also because a large portion of the clear sky coverage is over less populated regions such as at the poles and over the deserts. Thus, if only clear sky measurements were used, the available data over populated regions, where routine air quality monitoring is essential, would have been significantly fewer than $13 \%$. This would not have provided fre-
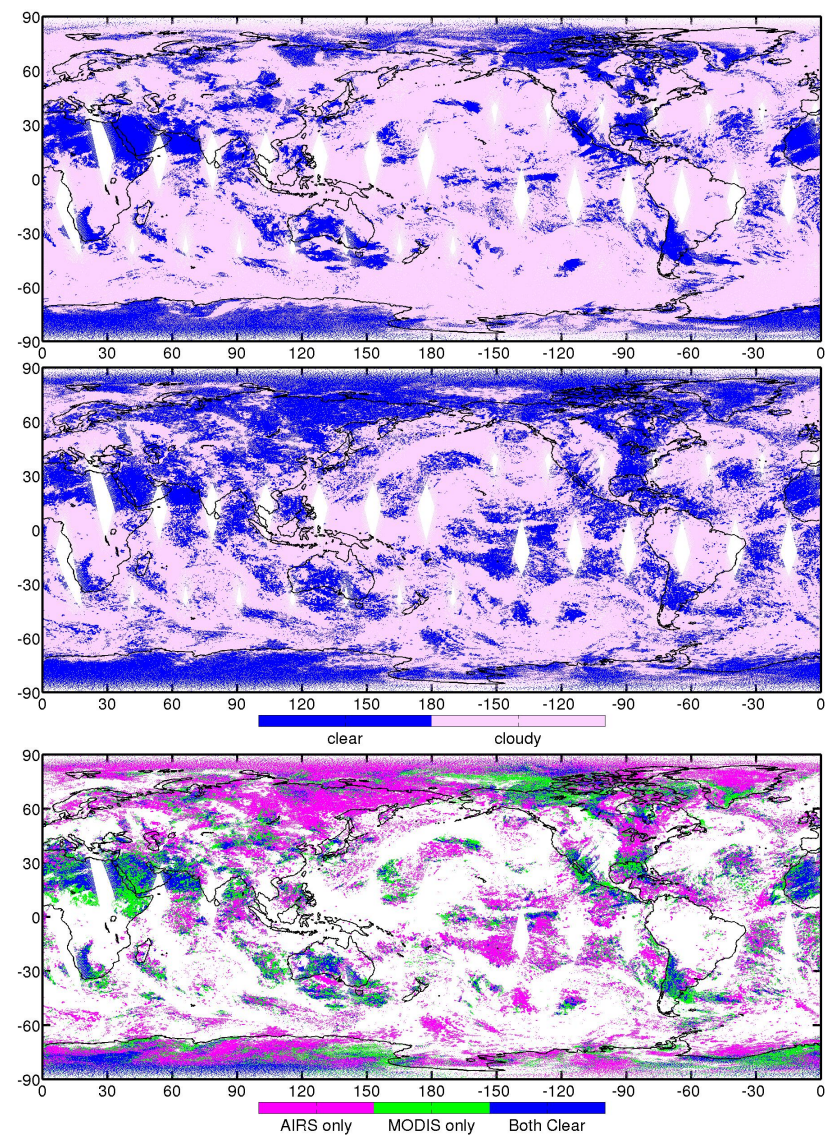

Fig. 2. AIRS clear coverage defined by the MODIS cloud mask (top panel), defined by AIRS L2 products where CloudFraction $=0$ (middle panel), and the differences between the top and middle panel (bottom panel).

quent enough coverage for air quality monitoring purposes over most regions.

\section{AIRS CO variability for clear sky and cloud-cleared scenes}

In this section, we discuss the $\mathrm{CO}$ differences between AIRS clear sky coverage using the MODIS cloud mask and cloudcleared data sets to assess the performances of AIRS cloud clearing and identify possible limitations. We analyze the statistics of the AIRS CO distribution and variability using clear pixels and cloud-cleared pixels independently. Note that the $\mathrm{CO}$ values for clear pixels are selected from AIRS V5 L2 CO data sets where the cloud-cleared radiances (CCRs) were used. Accurate $\mathrm{CO}$ values under clear sky conditions should be retrieved CO from Level-1 (L1) clear radiances. Using the $\mathrm{CO}$ retrievals from the CCRs as an approximation for clear sky conditions of the same pixels could cause some errors; however, we do not expect large differences between the two data sets. 

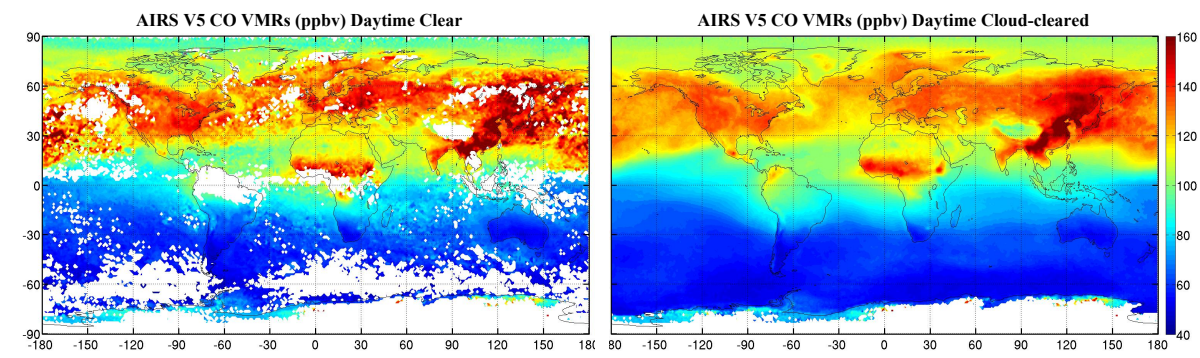

AIRS V5 CO VMRs (ppbv) Nighttime Clear
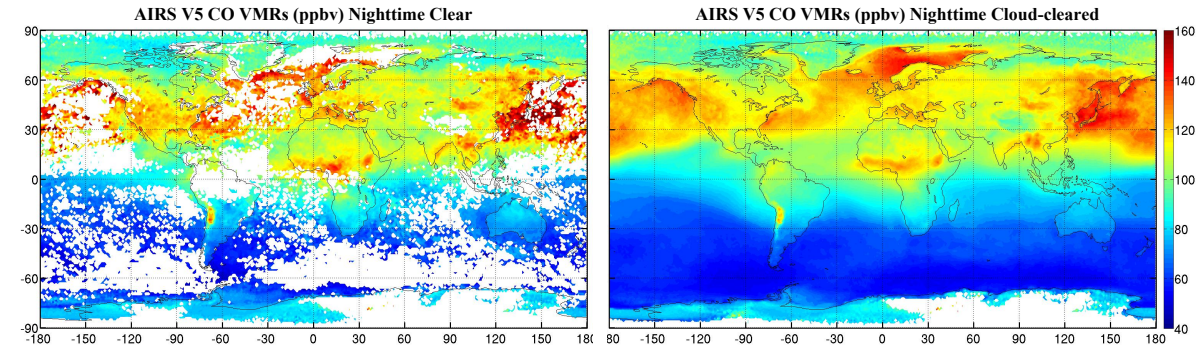

Fig. 3. The 3-month mean AIRS V5 CO VMRs (ppbv) at $500 \mathrm{hPa}$ for March to May 2006, showing the clear sky daytime cases (upper left panel), the clear sky nighttime cases (bottom left panel), the cloud-cleared daytime cases (upper right panel), and the cloud-cleared nighttime cases ( bottom right panel).

The monthly mean AIRS V5 CO VMR (volume mixing ratio) maps at $500 \mathrm{hPa}$ for March to May 2006 are shown in Fig. 3 with the clear daytime cases in the upper left panel, the clear nighttime cases in the bottom left panel, the cloud-cleared daytime cases in the upper right panel, and the cloud-cleared nighttime cases in the bottom right panel. Large areas of the earth are covered by clouds throughout the month as shown by the gaps in the left panels, demonstrating the need for AIRS cloud-cleared products for monitoring the environment. The elevated $\mathrm{CO}$ shows similar emission sources and transport patterns for both the clear sky cases (left panels) and the cloud-cleared cases (right panels). Note that the clear sky cases are embedded in the cloud-cleared cases under discussion. In general, the clear sky cases show higher values in the elevated $\mathrm{CO}$ regions than the cloudcleared cases, for both daytime and nighttime. The $\mathrm{CO}$ values for clear sky cases are lower in the clean regions than the cloud-cleared cases, and, therefore, the clear sky maps show better contrasts. Daytime CO values are generally higher than the nighttime values (compare the upper panels to the lower panels), which is due to the surface thermal contrast that increases the CO measurement sensitivity in the lower troposphere and, in turn, results in higher retrieved $\mathrm{CO}$ in the Northern Hemisphere (NH) in the spring (Deeter et al., 2007).

To understand the effects of the cloud clearing on the $\mathrm{CO}$ measurements, it is important to examine the information content of the $\mathrm{CO}$ measurements as described by the degrees of freedom for signal (DOFSs). AIRS operational CO DOFSs are calculated using a different formula from that commonly used in the community and described by Rodgers (2000). We computed the DOFSs in this study us- ing the Rodgers formula that is generally associated with the optimal estimation retrievals (Warner et al., 2010), even though the CO values are from AIRS Version-5 (V5) operational products using AIRS team retrievals (Susskind et al., 2003). Figure 4 shows AIRS optimal estimation CO DOFSs for the months of March to May 2006 for cloud-cleared cases (right panels) versus clear cases (left panels) and for daytime (upper panels) versus nighttime (lower panels). The high DOFS values for the cloud-cleared products range from 0.8 to 1.0 , and the DOFS values for the clear sky conditions go up to 1.2. This comparison indicates that the cloudclearing process may have reduced the DOFSs, although not by a large amount $(\sim 0.2)$, in the CO retrievals. Note also that the DOFSs over land are generally higher than over the oceans, and the daytime values are higher than nighttime values, which is due to the differences in surface thermal contrast.

The $10 \mathrm{yr}$ variability of tropospheric CO VMRs at $500 \mathrm{hPa}$ during daytime from 2003 through 2012 is summarized in Fig. 5a, using daily mean values for clear sky (blue curves) and cloud-cleared (red curves), and for $\mathrm{NH}$ land, $\mathrm{NH}$ ocean, Southern Hemisphere (SH) land, and SH ocean. The yellow line shows the difference between the clear sky cases and cloud-cleared cases (i.e., cloud-cleared minus clear). The least square linear fits for the clear and cloud-cleared cases are plotted to indicate the short-term $\mathrm{CO}$ trends, but they are not discussed until the next section. Because the AIRS team is no longer distributing V5 products beyond the end of February 2013 (since then replaced by V6 products), we did not use data beyond 2012 in this study. Globally, there is no large bias from cloud clearing, except over the $\mathrm{SH}$ land, evident from $10 \mathrm{yr}$ of AIRS CO data records. The CO 

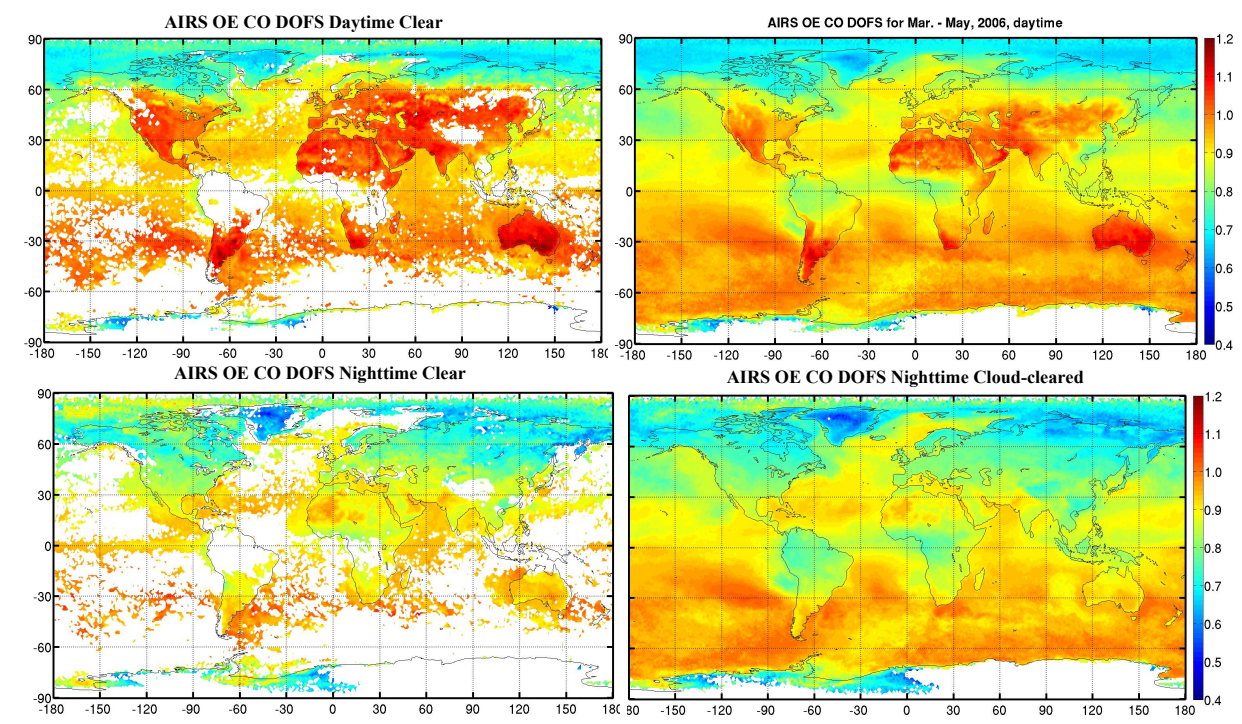

Fig. 4. AIRS optimal estimation CO DOFS values for the months of March to May 2006, for cloud-cleared cases (right panels) versus clear cases (left panels) and for daytime (upper panels) versus nighttime (lower panels).

differences between cloud-cleared and clear are less than $\pm 5 \mathrm{ppbv}$ (parts per billion by volume) for the $\mathrm{NH}$ land and ocean and $\sim 0$ to $-10 \mathrm{ppbv}$ for the SH ocean, and $\sim 0$ to $20 \mathrm{ppbv}$ over the SH land. We emphasize that cloud clearing increases global coverage significantly making daily monitoring possible, and without causing large biases in the tropospheric CO distribution.

Over land, for both $\mathrm{NH}$ and $\mathrm{SH}$, during the relatively low $\mathrm{CO}$ season (summer months) at daytime, the cloud-cleared $\mathrm{CO}$ values tend to overestimate the $\mathrm{CO}$ field by approximately 5 ppbv in the $\mathrm{NH}$ and by approximately $15-20 \mathrm{ppbv}$ in the SH. This is likely due to the fact that cloud clearing reduces the thermal contrast over land in the summer months, thus, reducing the sensitivity to the relatively low $\mathrm{CO}$ values in the lower troposphere over clean regions. This is consistent with the earlier discussion about the DOFS differences shown in Fig. 4. Additionally, the ranges of $\mathrm{CO}$ seasonal variations are generally larger over land $(\sim 30-35 \mathrm{ppbv}$ in the $\mathrm{NH}$ and $\sim 40-60 \mathrm{ppbv}$ in the $\mathrm{SH}$ ) than over ocean (125 ppbv). Previous studies (Warner et al., 2010; Yurganov et al., 2008) have suggested that AIRS CO tends to overestimate the $\mathrm{CO}$ field in the $\mathrm{SH}$ due to the use of a global a priori or first guess in the retrieval. This study points out that, under pure clear sky conditions, it is possible for AIRS to retrieve, over land, SH clean background $\mathrm{CO}$ values of approximately 40 ppbv.

Similarly to the above discussion, the nighttime variability of tropospheric CO VMRs at $500 \mathrm{hPa}$ from 2003 through 2012 is studied and shown in Fig. 5b. The nighttime CO differences between cloud-cleared and clear cases are smaller for the $\mathrm{NH}$ and $\mathrm{SH}$ land cases than for the daytime due to the reduced thermal contrast, whereas they are similar for the ocean $\mathrm{NH}$ and $\mathrm{SH}$ cases.

\section{Distinguishing $\mathrm{CO}$ recent emissions from the background using AIRS clear-sky measurements}

Emission inventories based on direct $\mathrm{CO}$ measurements have not been available except with the use of inverse modeling techniques (Pfister et al., 2005; Arellano et al., 2006; Kopacz et al., 2010). This study attempts to draw information on recent emissions from satellite $\mathrm{CO}$ data only to build toward the ultimate goal of monitoring fire activities in near-realtime using CO. AIRS CO-based biomass burning detection will complement the current real-time fire alarm system using MODIS thermal signals, because AIRS CO products are less constrained by smoke and heterogeneous clouds.

We use probability density functions (PDFs) to study the statistical properties of the $\mathrm{CO}$ distributions under various conditions. Figure 6 shows PDF plots of AIRS V5 CO VMRs for the $\mathrm{NH}$ land (upper left), $\mathrm{NH}$ ocean (upper right), $\mathrm{SH}$ land (lower left), and SH ocean (lower right), respectively, for the period of March to May 2006 and for daytime only. We note that the histograms for the $\mathrm{CO}$ distributions are not generally Gaussian and often show two peaks (see Fig. 6 top left and bottom left panels) over a CO population. The peaks at lower $\mathrm{CO}$ values are generally associated with the background (BG) $\mathrm{CO}$, whereas the peaks at the higher $\mathrm{CO}$ values are associated with the recent emissions (RE). We fit two Gaussian functions simultaneously for each histogram for clear (solid) or cloud-cleared (dashed) conditions. The Gaussian fits to the left in each panel (blue) represent a well-mixed background, whereas the right Gaussian fits to the right in each panel (red), which have higher $\mathrm{CO}$ values, represent the fresh emissions. We define the fresh emissions as the elevated $\mathrm{CO}$ that is seen by satellite instruments as plumes, but emitted and transported from the surface. 

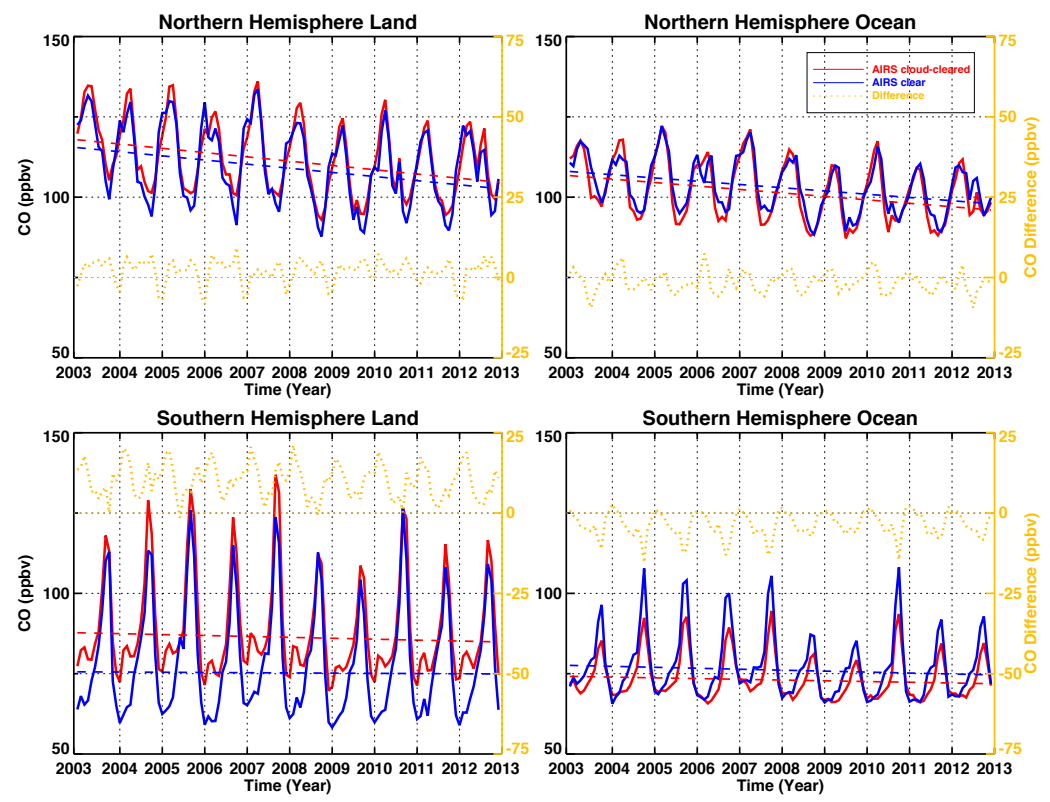

Fig. 5a. The $10 \mathrm{yr}$ variability of tropospheric CO VMRs (ppbv) at $500 \mathrm{hPa}$ from 2003 through 2012 using daily mean values for clear sky (blue curves) and cloud-cleared (red curves), and for NH land, NH ocean, SH land, and SH ocean. The yellow line indicates the differences between clear sky cases and cloud-cleared cases (cloud-cleared - clear). The linear fits for the clear and cloud-cleared cases are plotted to indicate the short-term $\mathrm{CO}$ trends.
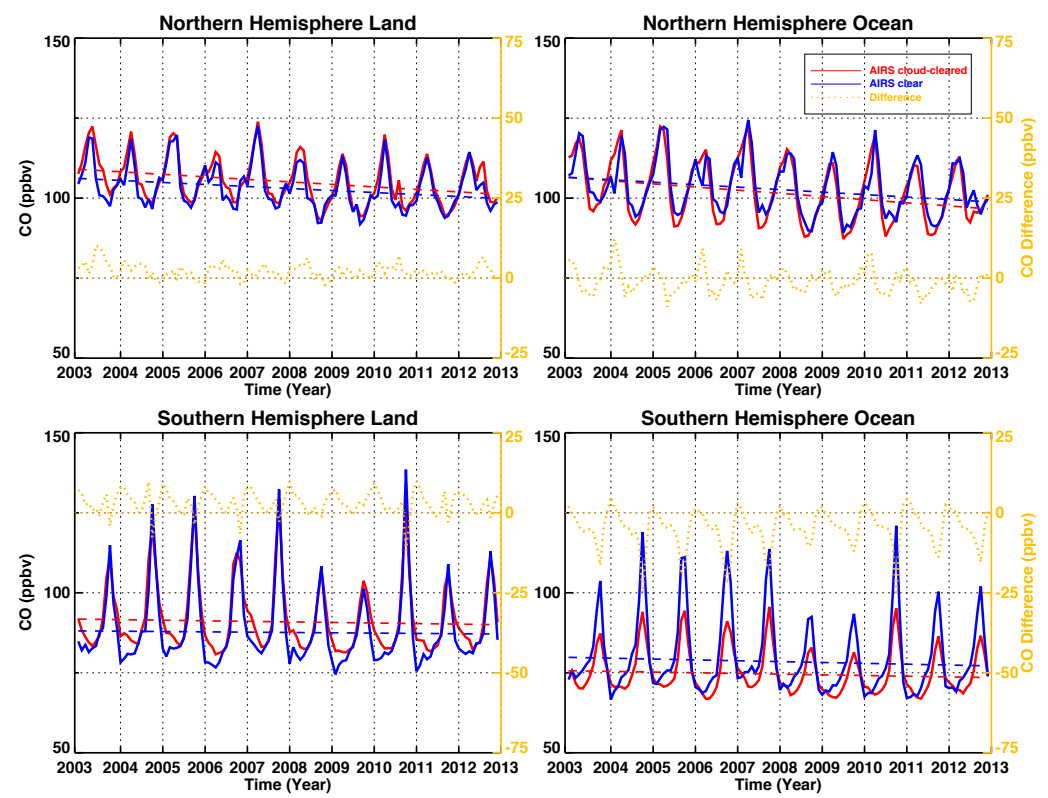

Fig. 5b. As Fig. 5a except for nighttime.

The fitted CO background PDFs (blue curves in Fig. 6) are approximately the same for clear (solid) and cloud-cleared (dotted) cases for both $\mathrm{NH}$ and $\mathrm{SH}$ oceans (see right panels in Fig. 6). The cloud-cleared PDFs (dotted curves) in the NH land show a single mode and a more Gaussian structure as opposed to the clear cases (solid curves), where a bi-modal feature separates recent emissions from the background $\mathrm{CO}$.
The SH land cases show the largest differences between clear and cloud-cleared cases where the cloud clearing masks the otherwise different two populations of background and recent emissions (see the lower left panel in Fig. 6). Note, however, this could be partly due to the large sampling differences over the biomass burning regions, where the MODIS 

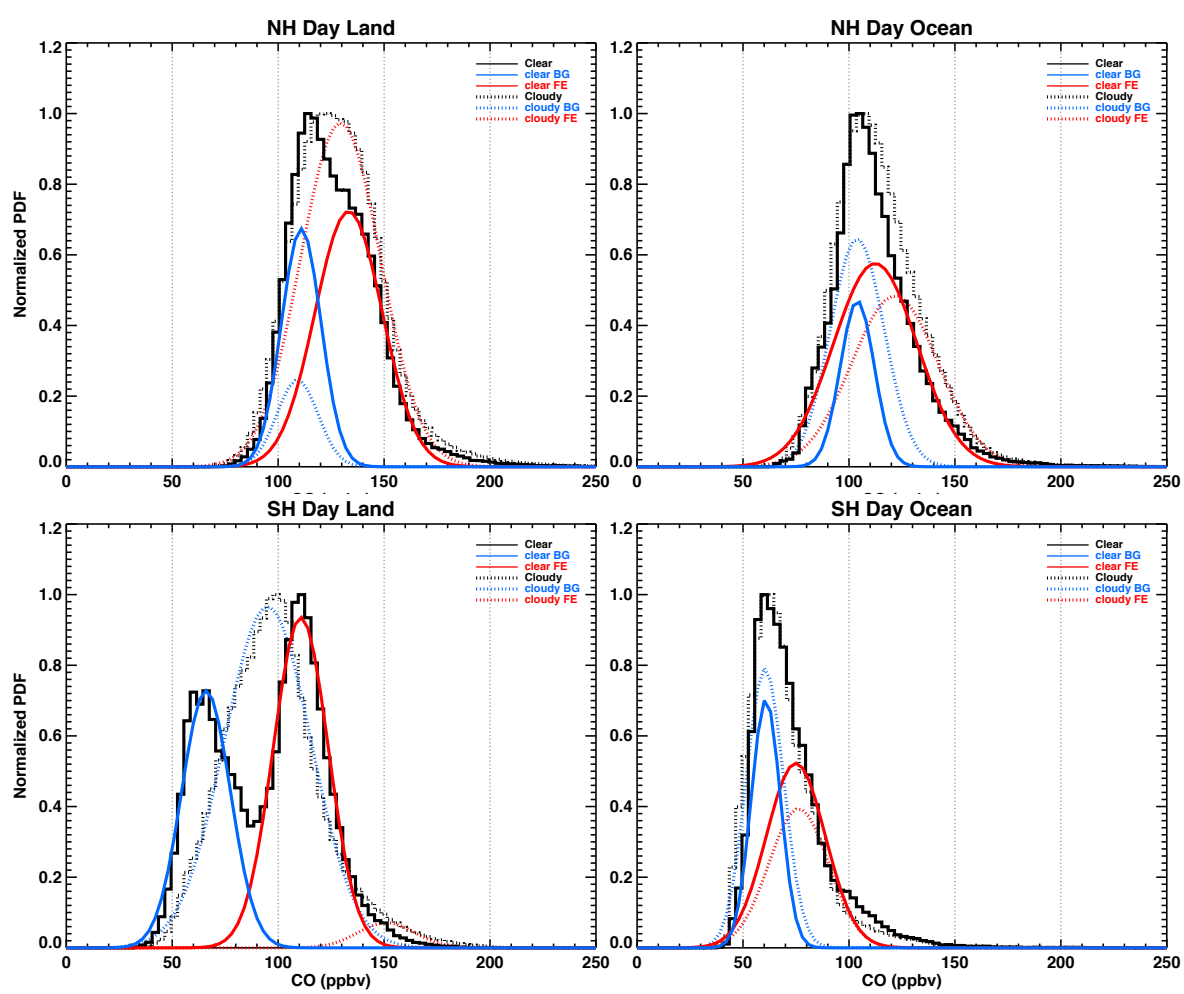

Fig. 6. The monthly mean CO VMRs for March to May, 2006, using PDFs for the NH land (upper left panel), NH ocean (upper right panel), SH land (lower left panel), and SH ocean (lower right panel), for daytime only.

cloud mask can mistakenly identify smoke as clouds, thus resulting in very few clear pixels.

The $\mathrm{CO}$ variability for the background and the recent emissions is analyzed separately in this section, and only the clear sky cases are discussed. We use the modes of the fitted Gaussian functions from each monthly PDF to represent the averaged $\mathrm{CO}$ values based on the fact that, for a Gaussian function, the mode is the same as the mean. The tropospheric CO histogram distributions can be considered, to a good accuracy, as the superposition of two Gaussian functions. Tropospheric CO variability from 2003 through 2012 is summarized in Fig. 7 for both the background values and the recent emissions for $\mathrm{NH}$ land (top left panel), $\mathrm{NH}$ ocean (top right panel), SH land (bottom left panel), and SH ocean (bottom right panel), respectively. The background values are shown in blue and the recent emissions in red. In general, decreasing $\mathrm{CO}$ trends in both the background and recent emissions are evident over most of the years, which agrees with results from previous studies (Worden et al., 2013; He et al., 2013).

The trends for the same period are calculated from the change in CO VMRs in ppbv per year, and the fitting parameters are listed in Table 1 for un-segregated clear sky conditions (leftmost column), un-segregated cloud-cleared (left second column), recent emissions (middle column), and background under clear conditions (right column). The trends are computed using a least squares linear fit. Addi-
Table 1. The rates of the reduction (negative numbers) and increase (positive numbers) of AIRS CO VMRs at $500 \mathrm{hPa}$ for daytime values for the clear and the cloud-cleared (left columns), and for the background values and the recent emissions from under clear con-

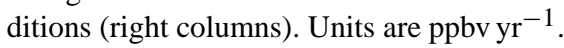

\begin{tabular}{lcc|cc}
\hline & $\begin{array}{c}\text { AIRS CO VMRs at 500 hPa } \\
\text { 2003-2012 daytime } \\
\text { un-segregated }\end{array}$ & $\begin{array}{c}\text { AIRS CO VMRs at 500 hPa } \\
\text { 2003-2012 daytime }\end{array}$ \\
\cline { 2 - 5 } & Clear & Cloud-Cleared & RE & BG \\
\hline NH land & -1.28 & -1.32 & -1.71 & -1.71 \\
NH ocean & -1.01 & -1.07 & -1.95 & -1.18 \\
SH land & -0.07 & -0.29 & -0.14 & -0.28 \\
SH ocean & -0.30 & -0.23 & -0.85 & -0.62 \\
\hline
\end{tabular}

tionally, we use only full years so the trend estimates are not affected by seasons. The trend is significant at greater than $2 \sigma$ everywhere except the background fit over the SH land $(1 \sigma)$ and the fresh emissions over the $\mathrm{SH}$ land, where the $\mathrm{CO}$ emissions are due to large and somewhat irregular biomass burning events.

The AIRS CO short-term trend in the NH from 2003 to the end of 2012 indicates a reduction of $-1.71 \mathrm{ppbv} \mathrm{yr}^{-1}$ at $500 \mathrm{hPa}$ for both the recent emissions and the background CO. Over the $\mathrm{NH}$ ocean, the transported recent emissions decrease faster than the background $\mathrm{CO}$ at $500 \mathrm{hPa}$ at a 

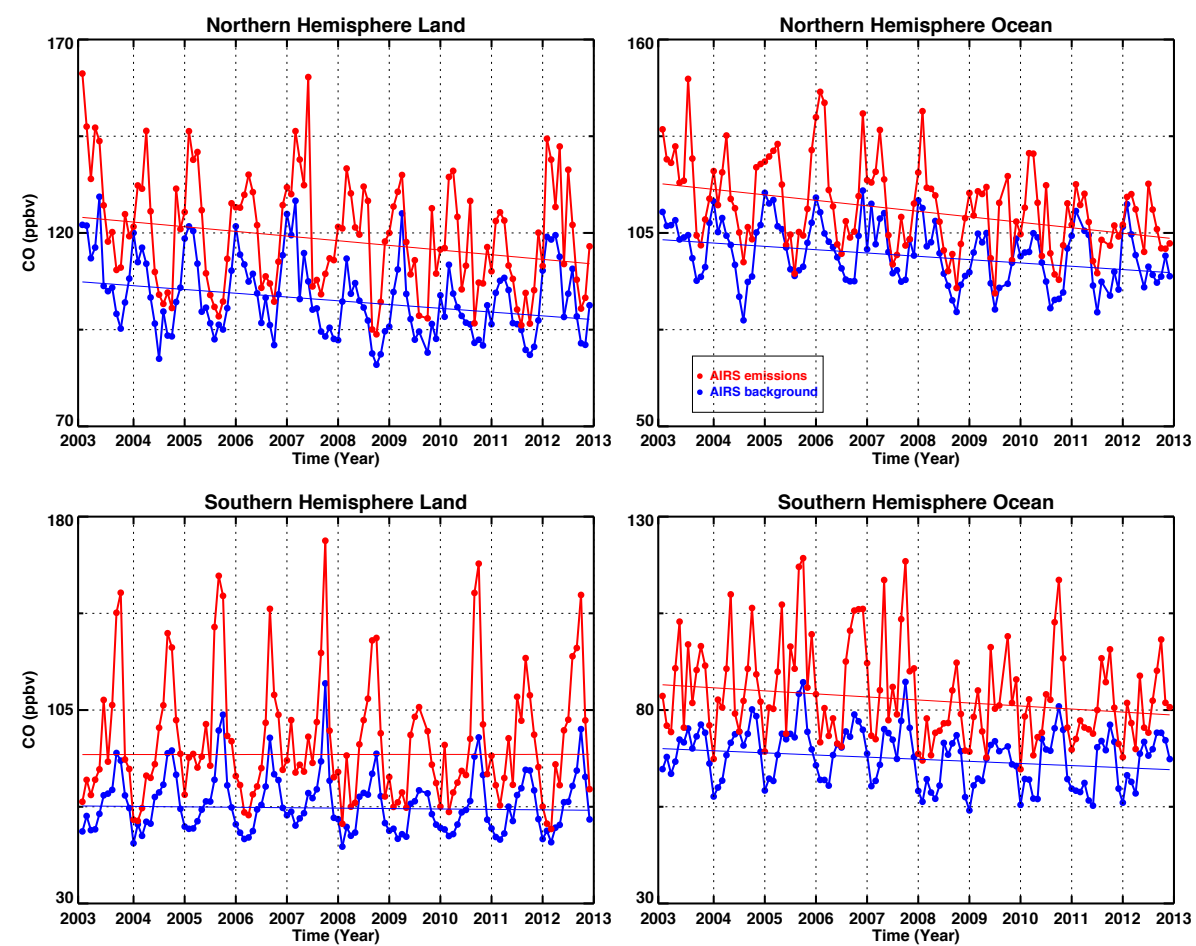

Fig. 7. Tropospheric CO variability at $500 \mathrm{hPa}$ from 2003 through 2012, which uses the modes of the fitted Gaussian functions for each monthly PDF to represent biases, for the recent emissions (red curves) and the background (blue curves), and for NH land (top left panel), $\mathrm{NH}$ ocean (top right panel), SH land (bottom left panel), and SH ocean (bottom right panel), respectively.

rate of $-1.95 \mathrm{ppbv} \mathrm{yr}^{-1}$ (emissions) and $-1.18 \mathrm{ppbv} \mathrm{yr}^{-1}$ (background). The background $\mathrm{CO}$ over the ocean decreases at a slower rate than the recent emissions; this may be due to a lack of mixing over ocean compared to over land. The $\mathrm{CO}$ rates of decrease are lower in the $\mathrm{SH}$ than in the $\mathrm{NH}$, with the recent emissions decreasing at a rate of $-0.14 \mathrm{ppbv} \mathrm{yr}^{-1}$ and background $\mathrm{CO}$ decreasing at $-0.28 \mathrm{ppbv} \mathrm{yr}^{-1}$, at $500 \mathrm{hPa}$ over land. Over the SH ocean, the $\mathrm{CO}$ decreasing trends are similar for the transported recent emissions $\left(-0.85 \mathrm{ppbv} \mathrm{yr}^{-1}\right)$ and the background val-

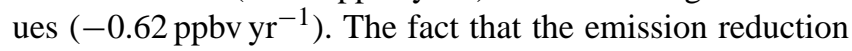
in the $\mathrm{NH}$ is larger compared to the $\mathrm{SH}$ indicates that the primary cause of the emission reduction is the change in pollution sources due to implementation of regulation regimes, and is also likely associated with economic slowdown in the last decade (Worden et al., 2013; He et al., 2013).

For comparison purposes, Table 1 also listed the trends for the un-segregated CO VMRs at $500 \mathrm{hPa}$ for clear (leftmost column) and cloud-cleared conditions (left second column), as also shown in Fig. 5. The short-term CO trends for clear and cloud-cleared retrievals are very similar (i.e., with differ-

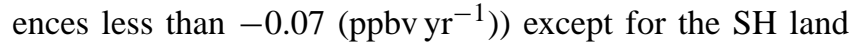
cases, where the difference is $-0.22\left(\mathrm{ppbv} \mathrm{yr}^{-1}\right)$; in both cases, the trends of cloud-cleared decrease faster than those of the clear. The trends for the segregated background CO and the recent emissions are larger than the un-segregated
CO trends, especially over land, where the trends of the recent emissions are nearly double of the clear un-segregated values.

To quantify the quality of the emission data from AIRS $\mathrm{CO}$, we compare them with existing biomass burning and anthropogenic emission inventories. The version 3 of the Global Fire Emissions Database (GFED3) biomass burning inventory (Van der Werf et al., 2010) used a revised version of the Carnegie-Ames-Stanford-Approach (CASA) biogeochemical model and improved satellite-derived estimates of area burned, fire activity, and plant productivity to calculate fire emissions for the 1997-2009 period on a $0.5 \times 0.5$ degree spatial resolution with a monthly time step. For November 2000 onwards, estimates were based on burned area, active fire detections, and plant productivity from the MODIS sensor. For anthropogenic emissions that exclude biomass burnings, we use the data that were produced as part of the MACC/CityZEN UE (MACCity) project and are available in the Ether/ECCAD-GEIA database. The data set MACCity is part of the Atmospheric Chemistry and Climate Model Intercomparison Project (ACCMIP), and focuses on the anthropogenic emissions from 1960 to 2010 with a spatial resolution of $0.5 \times 0.5^{\circ}$.

Figure $8 \mathrm{a}$ shows the variability of AIRS CO recent emissions (red dotted curves) and that of other inventory data (green dotted curves), i.e., the total amount of 


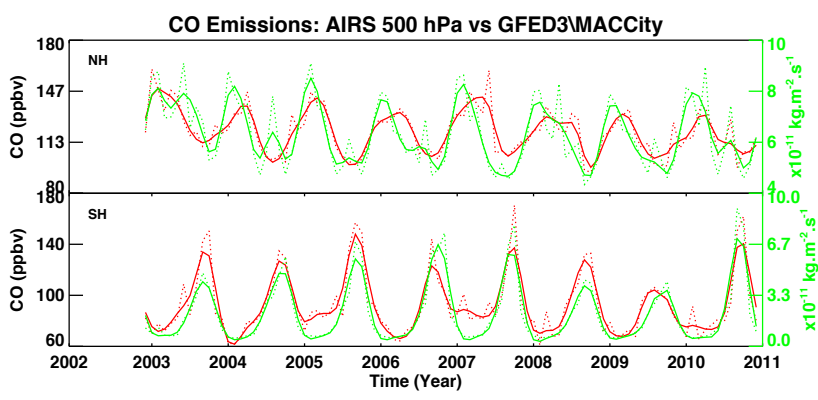

Fig. 8a. The variability of AIRS CO recent emissions (red dotted curves) and that of other inventory data (green dotted curves), i.e., the total amount of GFED3 biomass burning and MACCity anthropogenic emissions without biomass burning, for the $\mathrm{NH}$ (upper panel) and the SH (lower panel). The smoothed AIRS CO new emissions (red solid curve) and the smoothed inventories (green solid curve) are also shown. A second-degree polynomial is used for the smoothing.

GFED3 biomass burning and MACCity anthropogenic without biomass burning emissions, for the $\mathrm{NH}$ (upper panel) and the SH (lower panel). We have also filtered AIRS CO recent emissions (red solid curve), and the inventories (green solid curve), using a Butterworth third-order low-pass filter with a fast Fourier transform. Figure $8 \mathrm{~b}$ shows the $\mathrm{CO}$ emission inventories from the MACCity natural sources (red) and GFED3 anthropogenic sources (blue) for the NH (upper panel) and the SH (lower panel). The seasonal and interannual cycles agree very well in the time domain, although the relative magnitude differences cannot be quantified because the units of the two data sets are different (see Fig. 8a). In the $\mathrm{NH}$, the maximum $\mathrm{CO}$ peaks in late winter and early spring, while in some years $(2006,2007,2008$, and 2010) there is a secondary maximum in the summer likely due to biomass burning events. There is also a noticeable lag in the AIRS recent emissions in the $\mathrm{NH}$ compared to the inventories from 2006 to 2009 , possibly due to the fact the smoothed peaks in AIRS incorporated the summer burning events in these years. In the $\mathrm{SH}$, both the $\mathrm{CO}$ variability and the location of the high peaks agree very well between AIRS CO recent emissions and the inventories. There are two major reasons the two data sets differ. First, AIRS measurements are from $500 \mathrm{hPa}$ and the inventory data is the estimate of the net emission at the surface. Considering the $\mathrm{CO}$ lifetime in the troposphere is 1 to 3 months, there could be a delay from the time of the $\mathrm{CO}$ emission at the surface to it being observed at $500 \mathrm{hPa}$, and, additionally, the $\mathrm{CO}$ can be accumulated over some time. Second, the CO sensitivity from thermal sensors depends on the surface thermal contrasts (Deeter et al., 2007). Higher CO values are more likely to be observed in the summer months than in the spring months.

We compute correlations between AIRS CO VMR recent emissions and the total emission amount of GFED3 and MACCity inventories for the $\mathrm{NH}$ and $\mathrm{SH}$ as shown in Fig. 9

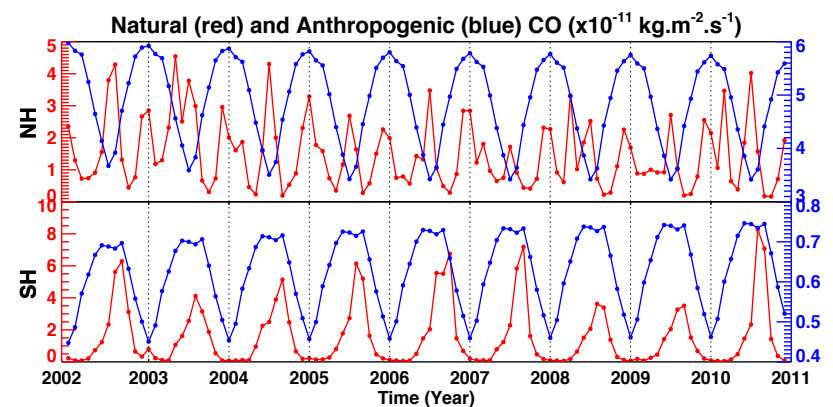

Fig. 8b. The CO emission inventories $\left(\mathrm{kg} \mathrm{m}^{-2} \mathrm{~s}^{-1}\right)$ from the MACCity natural sources (red) and GFED3 anthropogenic sources (blue) for the NH (upper panel) and the SH (lower panel).

left panel and right panel, respectively. The correlation coefficients are 0.726 for the NH and 0.915 for the SH. The higher correlation coefficient in the SH land cases is due to the fact that most of the recently emitted $\mathrm{CO}$ is from large and persistent fires, which are easier to detect by satellite sensors. In the $\mathrm{NH}$, the non-biomass burning anthropogenic emissions are more difficult to quantify since the sensitivity of the thermal sensors in the boundary layer (where pollution emission is high) is low. The high degree of agreement between emissions identified using only AIRS CO and using independent inventory sources (as shown in Fig. 9) demonstrates the validity of this approach to separate recent emission from the background $\mathrm{CO}$ using one satellite data set.

\section{Summary}

The goal of this study is to understand the global CO variability and short-term trends for the CO background values and recent emissions separately. We use an innovative approach to separate statistically the recently emitted $\mathrm{CO}$ from the background $\mathrm{CO}$ in the satellite data sets by using PDF analyses. We have demonstrated that this technique works well by showing high correlation between the AIRS CO emissions we obtained and the established inventory database (i.e., GFED3 and MACCity) with correlation coefficients of 0.726 in the $\mathrm{NH}$ and 0.915 in the $\mathrm{SH}$.

To ensure that we used the highest quality data for this study, we examined a potential error source due to the treatment of clouds in AIRS retrieval algorithm. We first identified AIRS clear sky single FOV pixels by using collocated MODIS cloud masks such that in each AIRS pixel $99 \%$ of MODIS pixels are flagged as being clear. We found that, overall, there is little difference in the location of the elevated $\mathrm{CO}$ plumes between the clear sky cases and the cloud-cleared retrievals. Under clear sky conditions, however, we showed the DOFSs are higher than for the cloud-cleared cases. Although the $\mathrm{CO}$ values do not exhibit high biases between the clear sky and cloud-cleared conditions when statistically averaged for the $\mathrm{NH}$ land, $\mathrm{NH}$ ocean, and $\mathrm{SH}$ ocean, the $\mathrm{CO}$ 


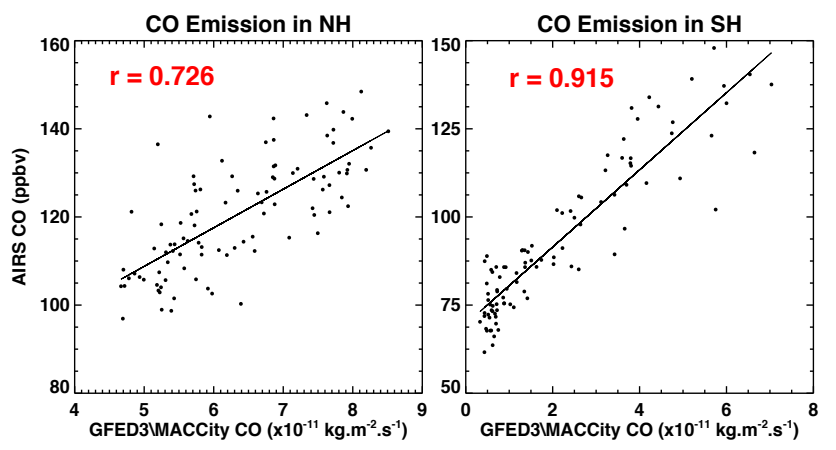

Fig. 9. The correlations between AIRS CO VMRs (ppbv) recent emissions at $500 \mathrm{hPa}$ and the total emission amount of GFED3 and MACCity inventories for the NH (left panel) and SH (right panel).

variability for clear sky cases is better represented. Therefore, we only used clear sky cases for the variability and short-term trend studies in Sect. 4.

Acknowledgements. This study is supported by the NASA Earth Sciences through ROSES by the Climate Record Uncertainty Analysis Program (NNX11AL22A), and by a sub-contract by the NASA JPL AIRS team (2009-2010). We have also been partially supported by the RTRA/STAE foundation from Toulouse, France. The authors wish to thank AIRS and MODIS science teams and Ether for the wonderful products that made these measurements possible.

Edited by: B. N. Duncan

\section{References}

Ackerman, S. A., Strabala, K. I., Menzel, W. P., Frey, R. A., Moeller, C. C., and Gumley, L. E.: Discriminating clear sky from clouds with MODIS, J. Geophys. Res., 103, 32141-32157, 1998.

Arellano, A. F. and Hess, P.: Sensitivity of Top-Down Estimates of CO sources to GCTM Transport, Geophys. Res. Lett., 33, L21807, doi:10.1029/2006GL027371, 2006.

Arellano Jr., A. F., Raeder, K., Anderson, J. L., Hess, P. G., Emmons, L. K., Edwards, D. P., Pfister, G. G., Campos, T. L., and Sachse, G. W.: Evaluating model performance of an ensemblebased chemical data assimilation system during INTEX-B field mission, Atmos. Chem. Phys., 7, 5695-5710, doi:10.5194/acp-75695-2007, 2007.

Aumann, H. H., Chahine, M. T., Gautier, C., Goldberg, M., Kalnay, E., McMillin, L., Revercomb, H., Rosenkranz, P. W., Smith, W. L., Staelin, D., Strow, L., and Susskind, J.: AIRS/AMSU/HSB on the Aqua Mission: Design, Science Objectives, Data Products and Processing Systems, IEEE T. Geosci. Remote, 41, 253-264, 2003.

Beer, R.: TES on the Aura mission: scientific objectives, measurements, and analysis overview, IEEE T. Geosci. Remote, 44, 1102-1105, 2006.

Chahine, M. T.: Remote sounding cloudy atmospheres. I. The single cloud layer, J. Atmos. Sci., 31, 233-243, 1974.
Chahine, M. T.: Remote sounding cloudy atmospheres. II. Multiple cloud formations, J. Atmos. Sci., 34, 744-757, 1977.

Clerbaux, C., Turquety, S., and Coheur, P. F.: Infrared remote sensing of atmospheric composition and air quality: Towards operational applications, C. R. Geosci., 342, 349-356, doi:10.1016/j.crte.2009.09.010, 2010.

Deeter, M. N., Edwards, D. P., Gille, J. C., and Drummond, J. R.: Sensitivity of MOPITT observations to carbon monoxide in the lower troposphere, J. Geophys. Res., 112, D24306, doi:10.1029/2007JD008929, 2007.

Drummond, J. R.: Novel correlation radiometer: The length modulated radiometer, Appl. Optics, 28, 2451-2452, 1989.

Emmons, L. K., Deeter, M. N., Gille, J. C., Edwards, D. P., Attié, J.-L., Warner, J., Ziskin, D., Francis, G., Khattatov, B., Yudin, V., Lamarque, J.-F., Ho, S.-P., Mao, D., Chen, J. S., Drummond, J., Novelli, P., Sachse, G., Coffey, M. T., Hannigan, J. W., Gerbig, C., Kawakami, S., Kondo, Y., Takegawa, N., Schlager, H., Baehr, J., and Ziereis, H.: Validation of Measurements of Pollution in the Troposphere (MOPITT) CO retrievals with aircraft in situ profiles, J. Geophys. Res., 109, D03309, doi:10.1029/2003JD004101, 2004.

Emmons, L. K., Pfister, G. G., Edwards, D. P., Gille, J. C., Sachse, G., Blake, D., Wofsy, S., Gerbig, C., Matross, D., and Neìde ìlec, P.: Measurements of Pollution in the Troposphere (MOPITT) validation exercises during summer 2004 field campaigns over North America, J. Geophys. Res., 112, D12S02, doi:10.1029/2006JD007833, 2007.

Fisher, J. A., Jacob, D. J., Purdy, M. T., Kopacz, M., Le Sager, P., Carouge, C., Holmes, C. D., Yantosca, R. M., Batchelor, R. L., Strong, K., Diskin, G. S., Fuelberg, H. E., Holloway, J. S., Hyer, E. J., McMillan, W. W., Warner, J., Streets, D. G., Zhang, Q., Wang, Y., and Wu, S.: Source attribution and interannual variability of Arctic pollution in spring constrained by aircraft (ARCTAS, ARCPAC) and satellite (AIRS) observations of carbon monoxide, Atmos. Chem. Phys., 10, 977-996, doi:10.5194/acp10-977-2010, 2010.

He, H., Stehr, J. W., Hains, J. C., Krask, D. J., Doddridge, B. G., Vinnikov, K. Y., Canty, T. P., Hosley, K. M., Salawitch, R. J., Worden, H. M., and Dickerson, R. R.: Trends in emissions and concentrations of air pollutants in the lower troposphere in the Baltimore/Washington airshed from 1997 to 2011, Atmos. Chem. Phys., 13, 7859-7874, doi:10.5194/acp-13-7859-2013, 2013.

Heald, C. L., Jacob, D. J., Fiore, A. M., Emmons, L. K., Gille, J. C., Deeter, M. N., Warner, J. X., Edwards, D. P., Crawford, J. H., Hamlin, A. J., Sachse, G. W., Browell, E. V., Avery, M. A., Vay, S. A., Westberg, D. J., Blake, D. R., Singh, H. B., Sandholm, S. T., Talbot, R. W., and Fuelberg, H. E.: Asian outflow and transPacific transport of carbon monoxide and ozone pollution: An integrated satellite, aircraft, and model perspective, J. Geophys. Res., 108, 4804, doi:10.1029/2003JD003507, 2003.

Justice, C. O., Giglio, L., Korantzi, S., Owens, J., Morisette, J., Roy, D., Dcscloitres, J., Alleaume, S., Petitcolin, F., and Kaufman, Y.: The MODIS fire products, Remote Sens. Environ., 83, 244-262, 2002.

Kim, P. S., Jacob, D. J., Liu, X., Warner, J. X., Yang, K., Chance, K., Thouret, V., and Nedelec, P.: Global ozone-CO correlations from OMI and AIRS: constraints on tropospheric ozone sources, 
Atmos. Chem. Phys., 13, 9321-9335, doi:10.5194/acp-13-93212013, 2013.

Kopacz, M., Jacob, D. J., Fisher, J. A., Logan, J. A., Zhang, L., Megretskaia, I. A., Yantosca, R. M., Singh, K., Henze, D. K., Burrows, J. P., Buchwitz, M., Khlystova, I., McMillan, W. W., Gille, J. C., Edwards, D. P., Eldering, A., Thouret, V., and Nedelec, P.: Global estimates of CO sources with high resolution by adjoint inversion of multiple satellite datasets (MOPITT, AIRS, SCIAMACHY, TES), Atmos. Chem. Phys., 10, 855-876, doi:10.5194/acp-10-855-2010, 2010.

Lamarque, J.-F., Khattatov, B., Yudin, V., Edwards, D. P., Gille, J. C., Emmons, L. K., Deeter, M. N., Warner, J., Ziskin, D., Francis, G., Ho, S., Mao, D., and Chen, J.: Application of a bias estimator for the improved assimilation of Measurements of Pollution in the Troposphere (MOPITT) carbon monoxide retrievals, J. Geophys. Res., 109, D16304, doi:10.1029/2003JD004466, 2004.

Lin, M., Fiore, A., Horowitz, L. W., Cooper, O. R. R., Naik, V., Holloway, J. S., Johnson, B. J. J., Middlebrook, A. M., Oltmans, S. J. J., Pollack, I. B., Ryerson, T. B., Warner, J., Wiedinmyer, C., Wilson, J., and Wyman, B.: Transport of Asian ozone pollution into surface air over the western United States in spring, J. Geophys. Res., 117, D00V07, doi:10.1029/2011JD016961, 2012.

McMillin, L. M. and Dean, C.: Evaluation of a new operational technique for producing clear radiances., J. Appl. Meteorol., 21, 1005-1014, 1982.

Pfister, G., Hess, P. G., Emmons, L. K., Lamarque, J.-F., Wiedinmyer, C., Edwards, D. P., Petron, G., Gille, J. C., and Sachse, G. W.: Constraints on Emissions for the Alaskan Wildfires 2004 using data assimilation and inverse modeling of MOPITT CO, Geophys. Res. Lett., 32, L11809, doi:10.1029/2005GL022995, 2005.

Pradier, S., Attie, J.-L., Chong, M., Escobar, J., Peuch, V.-H., Lamarque, J.-F., Khattatov, B., and Edwards, D. P.: Evaluation of 2001 springtime CO transport over West Africa using MOPITT CO measurements assimilated in a global chemistry transport model, Tellus B, 58, 163-176, 2006.

Smith, W. L.: An improved method for calculating tropospheric temperature and moisture from satellite radiometer measurements, Mon. Weather Rev., 96, 387-396, 1968.
Susskind, J., Barnet, C., and Blaisdell, J.: Determination of atmospheric and surface parameters from simulated AIRS/AMSU/HSB sounding data: Retrieval and cloud clearing methodology, Adv. Space Res., 21, 369-384, 1998.

Susskind, J., Barnet, C. D., and Blaisdell, J. M.: Retrieval of atmospheric and surface parameters from AIRS/AMSU/HSB data in the presence of clouds, IEEE T. Geosci. Remote, 41, 390-409, 2003.

van der Werf, G. R., Randerson, J. T., Giglio, L., Collatz, G. J., Mu, M., Kasibhatla, P. S., Morton, D. C., DeFries, R. S., Jin, Y., and van Leeuwen, T. T.: Global fire emissions and the contribution of deforestation, savanna, forest, agricultural, and peat fires (19972009), Atmos. Chem. Phys., 10, 11707-11735, doi:10.5194/acp10-11707-2010, 2010.

Warner, J. X., Comer, M. M., Barnet, C. D., McMillan, W. W., Wolf, W., Maddy, E., and Sachse, G.: A Comparison of Satellite Tropospheric Carbon Monoxide Measurements from AIRS and MOPITT During INTEX-A, J. Geophys. Res., 112, D12S17, doi:10.1029/2006JD007925, 2007.

Warner, J. X., Wei, Z., Strow, L. L., Barnet, C. D., Sparling, L. C., Diskin, G., and Sachse, G.: Improved agreement of AIRS tropospheric carbon monoxide products with other EOS sensors using optimal estimation retrievals, Atmos. Chem. Phys., 10, 95219533, doi:10.5194/acp-10-9521-2010, 2010.

Worden, H. M., Deeter, M. N., Frankenberg, C., George, M., Nichitiu, F., Worden, J., Aben, I., Bowman, K. W., Clerbaux, C., Coheur, P. F., de Laat, A. T. J., Detweiler, R., Drummond, J. R., Edwards, D. P., Gille, J. C., Hurtmans, D., Luo, M., MartínezAlonso, S., Massie, S., Pfister, G., and Warner, J. X.: Decadal record of satellite carbon monoxide observations, Atmos. Chem. Phys., 13, 837-850, doi:10.5194/acp-13-837-2013, 2013.

Yurganov, L. N., McMillan, W. W., Dzhola, A. V., Grechko, E. I., Jones, N. B., and van der Werf, G. R.: Global AIRS and MOPITT CO measurements: Validation, comparison, and links to biomass burning variations and carbon cycle, J. Geophys. Res., 113, D09301, doi:10.1029/2007JD009229, 2008. 